\title{
A Correlational Study of Self-Efficacy and Ikigai Comparing Between Students Aiming To Study Medicine and Those Interested in Other Degrees
}

\author{
Nattapong Chitsongsawat and Pratchayapong Yasri \\ Roi Et Wittayalai School, Thailand
}

\begin{abstract}
Two psychological concepts are of importance to determine how school students are ready to proceed with their decision to continue their higher education. One is selfefficacy which is a person's particular set of beliefs that determine how well one can execute a plan of action in prospective situations. The other is ikigai which explains the reason for one's existence (i.e., the purpose of life). Although self-efficacy has been thoroughly examined, empirical evidence for ikigai among school learners is found missing. This study therefore was set to reveal statistical findings in relation to the association between these two concepts among those wanting to study medicine and those interested in other degrees. It adopted a quantitative approach using an online questionnaire containing 12 self-efficacy and 4 ikigai statements based on a 5-point Likert scale. The total number of respondents was 276 secondary school students. While t-test was used to determine the statistical difference of means, a correlational test was used to investigate the relationship between self-efficacy and ikigai. The statistical analysis revealed that the mean of ikigai attained by those aiming for medical schools was statistically greater than that of those aiming for other schools. In addition, there was a weak correlation between ikigai and self-efficacy at the significance level of 95\% $(\mathrm{r}=0.3)$. However, further analysis showed that the only aspect of self-efficacy that was found to be positively related to ikigai was verbal persuasion $(\mathrm{r}=0.3)$. In contrast, among those aiming for nonmedical degrees, only mastery experience positively correlated with ikigai $(r=0.3)$. This study raises concern about the possibility that words from others could affect the decision of those aiming to study medicine. However, those aiming for others tend to make this decision based on their own experience.
\end{abstract}

Keywords: Self-efficacy; ikigai; Medicine; Higher education 